\title{
Advancing Collaboration Engineering: New ThinkLets for Dyadic Problem Solving and an Application for Mobile Advisory Services
}

\author{
Schwabe, Gerhard ; Giesbrecht, Tobias ; Briggs, Robert O
}

\begin{abstract}
Security advisors explore a client's home to discover, document, explain, and recommend solutions for security problems. Evidence from the field shows that home-owners rarely follow through to implement better security. We re-imagine the advisory process from an information-transfer activity to a collaborative problemsolving activity. We use the precepts of collaboration engineering, including the Six Layer Model of Collaboration, to develop a new collaborative work system in which security experts and home owners work together to improve security. We provide evidence that the new work practice using the "SmartProtector" application based on new thinkLets for dyadic collaboration improves outcomes in the field. Results are interesting to three stakeholders. First, police officials, and other security advisors can use the approach to introduce collaborative security advisory services in their cities. Second, development teams for future advisory systems in any domain can use our approach to capture the design rationale for their systems. Third, collaboration engineers and researchers can use and expand on the thinkLets we codified for reuse in designing mobile advisory services.
\end{abstract}

DOI: https://doi.org/10.1109/HICSS.2016.102

Posted at the Zurich Open Repository and Archive, University of Zurich

ZORA URL: https://doi.org/10.5167/uzh-129484

Conference or Workshop Item

Originally published at:

Schwabe, Gerhard; Giesbrecht, Tobias; Briggs, Robert O (2016). Advancing Collaboration Engineering: New ThinkLets for Dyadic Problem Solving and an Application for Mobile Advisory Services. In: 49th Hawaii International Conference on System Sciences (HICSS 2016), Hawaii, 5 January 2016 - 8 January 2016, s.n..

DOI: https://doi.org/10.1109/HICSS.2016.102 


\section{Advancing Collaboration Engineering: New ThinkLets for Dyadic Problem Solving and an Application for Mobile Advisory Services}

\author{
Gerhard Schwabe \\ University of Zurich \\ schwabe@ifi.uzh.ch
}

\author{
Robert O. Briggs \\ San Diego State University \\ rbriggs@mail.sdsu.edu
}

\author{
Tobias Giesbrecht \\ University of Zurich \\ giesbrecht@ifi.uzh.ch
}

\begin{abstract}
Security advisors explore a client's home to discov$e r$, document, explain, and recommend solutions for security problems. Evidence from the field shows that home-owners rarely follow through to implement better security. We re-imagine the advisory process from an information-transfer activity to a collaborative problem-solving activity. We use the precepts of collaboration engineering, including the Six Layer Model of Collaboration, to develop a new collaborative work system in which security experts and home owners work together to improve security. We provide evidence that the new work practice using the "SmartProtector" application based on new thinkLets for dyadic collaboration improves outcomes in the field. Results are interesting to three stakeholders. First, police officials, and other security advisors can use the approach to introduce collaborative security advisory services in their cities. Second, development teams for future advisory systems in any domain can use our approach to capture the design rationale for their systems. Third, collaboration engineers and researchers can use and expand on the thinkLets we codified for reuse in designing mobile advisory services.
\end{abstract}

\section{Introduction}

Collaboration Engineering (CE) is an approach to designing collaborative work practices for high-value tasks and transferring them to practitioners to execute for themselves without ongoing support from a collaboration expert [35]. To date, CE has focused primarily on designing work practices for workshop-or meetingstyle collaboration [4]. In this paper, we bring CE to bear on another style of collaboration: dyadic mobile advisory services. Advisory services are common in a modern economy, for instance, in banks and travel agencies, in social welfare and in the health care sector. Domain experts advise non-expert clients on how to proceed toward high-stakes goals like financial independency, health, and justice.
In many sectors, organizations seek to implement structured advisory processes in order to make processes repeatable and measurable, hoping to make the quality more consistent, and to assure compliance with policies and regulations. Despite their prevalence, however, these efforts often meet with limited success [22:62 ff]. Advisors tend to practice unstructured, ad hoc, improvised, inconsistent, and incomplete processes, in part because that is the path of least resistance. We reasoned that, if we re-imagined the advisory process from an information transfer between expert and non-expert into a collaborative problem solving activity between expert and problem owner, it might be possible to design a structured process - one that prescribes effective activities for the advisor - that is nonetheless flexible, in that the advisor and the client can choose to vary the order in which they execute the activities, depending on the nature of the client's needs and interests. Such an approach could increase the value that clients and society reap from advisory services. We focused particularly on mobile advisory services, where a keyboard-driven application [e.g. 3] would not be useful to practitioners on the move.

For this paper, we focused specifically on security advisory services. Professional policemen in Germany and Switzerland offer free advisory services to show citizens how to make their homes safer, e.g. by securing a vulnerable door. However, unpublished data from a German state, and discussions with senior police officials indicate that only about twenty percent of all advised people really implement a solution after a consultation. Can we improve advice implementation by better advice-giving processes? This paper reports an action design research project where we systematically reengineered the interaction between the police consultant and the home owner. We reconceive home security advice engagements from transferring-expertknowledge-to-non-experts to a collaborative problem solving engagement. The paper offers two contributions:

1. We present an innovative solution for security advisory services in a structured manner. The SixLayer Model of Collaboration (SLMC) [2] is well suit- 
ed to present the design rationale and the design principles (both typical Design Science Research contributions) as a comprehensive whole. The resulting solution is more than a software application; it is a collaborative problem solving process supported by, and embedded in a software application.

2. We extend the concepts of collaboration engineering to a new domain: while collaboration engineering has typically focused on medium and large group collaboration, we now apply it to dyadic expert-laymen collaboration. While collaboration engineering normally focuses on stationary users, we apply it to users who are walking around a house as they collaborate.

We provide a brief literature review of security advising, and motivate the design goals. Then we position the work in design science research, and introduce collaboration engineering. In Section 4, we use the SLMC to elaborate the design of eight new thinkLets and of the SmartProtector application. Section 5 provides empirical data to demonstrate that the solution meets its design goals. Section 6 discusses the contributions of the paper and proposes future directions.

\section{Problem Background}

Humans sometimes need advice about complex situations [29], where they are frequently unable to formulate relevant questions for themselves, creating what Belkin called "an anomalous state of knowledge" [1]. In those situations empathetic human actors are better than automated search engines in providing timely and appropriate advice. Homeowners are frequently not aware of all the threats and issues related to keeping their house safe, and so may benefit from the advice of security experts.

Recent improvements in human-computer interfaces have enabled a new stream of research in several domains focused on improving the effectiveness of advice giving in face-to-face engagements. The banking industry, for example, seeks to recover lost reputation and trust by offering more-transparent advice to small investors [23]. New regulations require that they take the transfer of knowledge to their clients more seriously [15] and also better understand their clients' needs [18].

Threatened by internet self-service, travel agencies also struggle to change from "human booking interfaces" and sales organizations to providers of valuable advice about planning and executing a trip. They are exploring the use of special electronic maps that have been enhanced to provide collaborative planning tools and multimedia content to help clients express and refine their travel interests and goals [21].
In the public sector, some agencies are now exploring the use of advisory support systems where a skilled advisor can support a citizen with complex needs, e.g. a pregnant woman, to aggregate fragmented information and knowledge from multiple sources and to orient the citizen about her options and obligations $[13,29]$. Thus, organizations are exploring a number of ways to improve advice-giving with the use of modern devices such as table-top-computers or tablet computers.

However, studies reveal two recurring issues with these initiatives. First, introducing a computer may threaten the delicate personal relationship between advisor and client: both may lose touch with one another as they struggle to operate the computer or to understand the information presented to them [14]. Second, the dual nature of process-structure quickly becomes apparent in the field: A clear process structure may improve the quality and consistency of advice giving. However if the structure of the process doesn't happen to match the structure of the participants' thinking, both clients and advisors report the unpleasant sense of having been made a small part of a large machine [23]. Thus while the innate human need [28] for competence may be easily advanced, the other two needs for relatedness and autonomy may be threatened by inappropriately designed tools and overly-structured advisory processes.

Other academic disciplines have also struggled to understand and improve advice giving. Advice-giving is central, for example, to clinical psychology, where it provides a means for clients to understand their situation and ultimately enable them to help themselves $[6,36]$. Service Sciences and Marketing research talk about "service encounters" [31,33] and "value cocreation experience" [25]. Medical advice-giving distinguishes between the "perfect client" who is educated by the advisor to the extent that he can treat himself and the "perfect advisor" who has a complete knowledge of the client and therefore makes all decision for him [11].

Authors argue, however, that the perfect client is an illusion in complex life situations as there is not sufficient time to properly educate the clients [17]. On the other hand, bad experiences (e.g. in banking advisory services), the limited cognitive and physical resources of the advisor, and the general spirit of time impose limits to the model of the perfect advisor. Thus in keeping with other recent efforts to professionalize advice giving $[9,16]$ we view advice giving as joint problem solving with distinct roles: The client is the expert on his or her problems which the advisor needs to understand in order to propose a solution; advisor is the expert on potential solutions that the clients need to understand in order to make a conscious choice. This 
view requires an extensive knowledge exchange. Typically this knowledge exchange is moderated by the advisor [13]. If we take this perspective, advice giving can be viewed and systematically engineered as a special kind of collaboration.

Most issues raised in other areas of advice giving are also true for home security advice. However home security advice has one additional aspect: important information "sticks" to the home, so the advisor normally offers this advice in the client's home and interacts both with the client and the natural environment (e.g. a window). In order to understand the problems, the advisor and the home-owner tour the house, trying to understand where a burglar could break in. The mobile aspect of this problem analysis process creates a set of new challenges: Giesbrecht et al. [12] point out that advisors tend to forget problems on the way through the house, so in the final discussion (typically at the kitchen table), the client and the advisor discuss only a subset of the existing security problems. The resulting documentation of problems and solutions is typically incomplete, which leaves some risks unaddressed, and yet sometimes clients still appear to be overwhelmed by the volume of information and services they receive. Furthermore IT-usage while standing and walking around requires different devices, different input patterns (keyboard input is awkward), increased efforts to maintain personal relationships (e.g. through maintaining eye-contact) and a different process design [7].

In a first pilot study, Giesbrecht et al [12], show that applying an appropriately designed tool reduces the number of forgotten problems and improves the documentation. However the tool is only part of the solution; the other part is an appropriately designed work processes - a way to use the tool to create value. Thus we define our artifact "mobile advisory service" as a work system, in which a mobile human advisor enables a client to help himself. Before we look at mobile advisory services in detail, the next section will introduce the design science research method applied and the data collection.

\section{Table 1. The Six Layer Model of Collaboration}

(Adapted from [3]).

\begin{tabular}{|c|c|}
\hline Layers & Description \\
\hline $\begin{array}{l}\text { Collaboration } \\
\text { Goals }\end{array}$ & $\begin{array}{l}\text { A goal is a desired state or outcome. Deals with group goals, private goals, and goal con- } \\
\text { gruence - the degree to which individuals perceive that working toward group goals will be } \\
\text { instrumental to attaining private goals. Collaboration is defined as joint effort toward a } \\
\text { group goal. Addresses motivation, group formation, commitment, productivity, satisfaction, } \\
\text { and other goal-related phenomena }\end{array}$ \\
\hline $\begin{array}{l}\text { Group } \\
\text { Deliverables }\end{array}$ & $\begin{array}{l}\text { A deliverable is a tangible or intangible artifact or outcome produced by the group's labor. } \\
\text { Deals with issues of quality, creativity, effectiveness, efficiency, and other product-related } \\
\text { phenomena. Teams create deliverables to achieve collaboration goals. }\end{array}$ \\
\hline $\begin{array}{l}\text { Group } \\
\text { Activities }\end{array}$ & $\begin{array}{l}\text { Activities are sub-tasks that, when completed, yield the products that constitute attainment } \\
\text { of the group goal. Deals with what groups must do to achieve their goals: sequences of steps } \\
\text { that constitute decision-making and problem-solving approaches. Teams move through ac- } \\
\text { tivities to create group deliverables. }\end{array}$ \\
\hline $\begin{array}{l}\text { Group } \\
\text { Procedures }\end{array}$ & $\begin{array}{l}\text { Group Procedures are the methods, strategies, and tactics a group uses to execute its work. } \\
\text { A sequence of procedures characterizes a group moves toward its goals. Procedures are } \\
\text { considered in two sub-layers: Patterns of collaboration (Generate, reduce, clarify, organize, } \\
\text { evaluate, and build commitment); and Collaboration Techniques for invoking useful varia- } \\
\text { tions on those patterns of collaboration (e.g. ThinkLets design patterns). Teams execute } \\
\text { techniques to invoke patterns of collaboration to move through group activities. }\end{array}$ \\
\hline $\begin{array}{l}\text { Collaboration } \\
\text { Tools }\end{array}$ & $\begin{array}{l}\text { Collaboration tools are artifacts or apparatus used in performing an operation for moving a } \\
\text { group toward its goals. Deals with designing, developing, configuring, deploying, and using } \\
\text { tools and technologies in support of group efforts. Teams use tools to instantiate collabora- } \\
\text { tion techniques. }\end{array}$ \\
\hline $\begin{array}{l}\text { Collaborative } \\
\text { Behaviors }\end{array}$ & $\begin{array}{l}\text { Collaborative Behaviors are the things people actually say and do with their tools to instan- } \\
\text { tiate group procedures. This area considers the observable actions and reactions of team } \\
\text { members making joint efforts toward a group goal, with a focus on guidance for and con- } \\
\text { straints on those behaviors to optimize collaboration processes for goal attainment and satis- } \\
\text { faction }\end{array}$ \\
\hline
\end{tabular}




\section{Research Method and Data Collection}

We started the action design research project [30] with the Zurich city police in 2012. Action design research combines an organizational and technical intervention and iterates through four phases:

I. problem formulation, II. building, intervention and evaluation, III. reflection and learning, and IV. formalization of learning. In the first half year the project focused on gathering data about the problems with security advisory sessions by observing advisory sessions and by interviewing security advisors and potential clients. Then we designed a first testable "proof-ofconcept" prototype using scenario based design [27]. This first prototype was tested in 2013 with the two Zurich city security advisors and 12 clients. The detailed procedures and results of the test were reported in Giesbrecht et al. [12]. After the test the prototype went through further smaller iterations of improvements and tests and was handed over to the security advisors for pilot use. In 2014 two advisors from the state of Zurich joined the team. As this required their training, all the knowledge on existing work-practices was systematically collected, discussed and linked to literature. The result was a first codification of work practices in the form of thinkLets (design patterns or techniques for collaborative work practices) [19,34] and a framework for transferring them to the two new security advisors. They were then tested with police advisors in the field, who provided feedback. Based on this feedback a new version of the collaborative work process was then developed.

We used precepts from $\mathrm{CE}$ to guide our design processes. There can be hundreds of concerns to which a collaboration engineer must attend when designing a new collaborative work practice. To reduce cognitive load and increase the degree to which these concerns are thoroughly addressed, collaboration engineers guide design processes with the SLMC (ref. Table 1). The SLMC considers a collaborative work practice at six levels of abstraction. Designers must make design choices at one level before design choices can be made at the next lower level. In some cases limits at a lower level may constrain design choices at a higher level. For example, a collaboration engineer could not select a collaboration technique at the Procedures Layer if the technologies required to instantiate the technique were not available at the Tools Layer.

The success of the Zurich pilot raised the interest of other Swiss cantonal polices and they agreed to test it in in June 2014. The data provided in this paper reports on those tests. The re-engineered security advice was validated in a field test with 6 advisors and 12 clients. The clients were volunteers recruited through an offer posted at a digital market-place, and were paid $60 \mathrm{CHF}$ for their participation. The clients were between 22 and 62 years old; four were female and eight male. The advisors were experienced police security advisors from several Swiss Cantons and were between 52 and 61 years old; all were male and none of them had previously used the SmartProtector or other technology to support their advisory sessions.

The advisors received one day of training where they got acquainted with the new advice approach, the thinkLets and the tools. The training consisted of three parts: In the first part, they received a general introduction to advice-giving. Then they were introduced to the procedures, the corresponding tool functionalities and the scripts for each procedure. Finally, they finished with practice sessions. In a role game, each advisor played the role of a client in one session, and played the role of an advisor in another.

The first training we conducted with the police advisors failed because some advisors would not accept the new work process from academics, whom they did not believe to be credible. In subsequent training sessions, we asked an experienced advisor to serve as a co-educator. With that, the trainee advisors accepted the new process and the training.

The actual test was situated in an empty housing block with several apartments available for the test. The recruited clients were told to imagine they had bought the apartment and now wanted to make it safer before moving in. The test applied experimental techniques in a within-subject-design, i.e. each client participated in one conventional advice session, and one SmartProtector advice session. The order of treatments was randomized. Each advisor ran two conventional advice sessions and two SmartProtector advice sessions. After their advice sessions, each client responded to a questionnaire, and was interviewed by a researcher. Researchers conducted one-on-one interviews with advisors at the end of the day, and each advisor responded to a questionnaire. The questionnaire was a mixture of advisory-specific questions and general questions based on established instruments.

\section{Solution}

In this section we apply the layers of the Six Layer Model of Collaboration to security advisory service. At each layer, we describe the as-is- situation of conventional advice giving and the to-be-situation of reengineered and computer-supported security advice.

Collaboration Goals: As discussed in the background section, it is the goal of the collaborative security advice processes to enable citizens to make their homes more secure to threats like home intrusion, burglary, assault. This requires that the citizens understand 
both the problem and the solution. This is the goal of the as-is and the to-be situation.

Group Deliverables: The most important output of the security advice process is a security plan. A security plan contains a list of security problems evaluated for degree of risk, and corresponding solutions for each problem, e.g. a vulnerable door and a specific proposal for how to improve the security of that door. In the asis advisory sessions (without application and thinkLet support), this content is presented in a standard printed, annotated brochure. The brochure contains standard problems and standard solutions. The security advisor writes on this brochure a few keywords on some specific actions the clients should take. The rest of the meeting content is stored only in the heads of the client and the advisor.

In our SmartProtector-based approach, clients receive a document that links annotated photographs of their own specific security problems (e.g. an unsafe window) with specific security solutions from a product database (e.g. pictures of a particular lock or a different kind of window). The solutions are prioritized in a two-by-two matrix by implementation dependencies - which problems have to be fixed before others can be fixed - and by severity - the degree of threat they present to the overall security of the house.

Group activities: We identified four core activities for the collaborative security advisory process that were the same for both the as-is and to-be: when security advisors arrive at a client's house, they first establish a personal relationship in the introduction phase. Next, they create a shared understanding of the client's needs in the initiation phase. In the subsequent exploration phase, the security advisor explores the house with the client to find possible weaknesses. In the final planning phase, the security advisor sits down at the client's kitchen table and they develop a plan of what should be done.

Group procedures: In the introduction phase of the as-is conventional session, the advisor introduces himself, and summarizes the overall advisory process for the client. The initiation phase consists of unstructured conversation to determine the client's security concerns. In the exploration phase, the client accompanies the advisor on a walking tour of the inside and the outside of the house to find security-relevant objects. The advisor informally assesses the security state of each object. The next actions are not consistently implemented. The advisor may or may not take notes on the security state of the object. He may or may not explain a discovered security problem to the client. While this flexibility may suit the immediate needs of the advisor, it raises a set of problems for the client: Neither the assessment process nor the resulting information pro- cess are transparent to the client [7]. This limits his involvement in the collaboration, and impairs his understanding of, trust in, and ability to implement recommended solutions. Furthermore, advisors are overconfident in their ability to remember the security threats they observed and the solutions discussed during the exploration phase. As Giesbrecht et al. [12] show, they tend to forget many issues during the planning session. The planning session therefore tends to be rather short. The advisor and the client revisit the problems about which the advisor made notes, and those that the advisor remembers when presenting the standard brochures to the client. In the end, the advisor summarizes the most important measures they discussed with handwritten notes on the main brochure and hands it over to the client. He then may or may not ask if there are any other issues before he says goodbye.

Our SmartProtector-based solution, by contrast, provides a scaffold for a better structuring of the advisory process, and a better means for documenting the security state of security-relevant objects. In the course of this project, we codified eight new thinkLets for collaborative advisory processes. Previous thinkLets [e.g. 4] were designed to support larger groups and were not useful for dyadic advisory sessions. The structure of the thinkLets follows the suggestion of Briggs et al. [5]. The introduction phase of the advisory process is similar to the one of conventional advisory sessions in order to clarify expectations and build commitment to the subsequent phases. In the initiation phase, the advisor and client generate a list of the homeowner's security concerns using the "Determine Needs" - technique (the thinkLets, or techniques, that we developed for advisory services are summarized in Table 2). During the exploration phase the client and the advisor tour the house together to generate a list of security relevant objects that pose security threats. If they find a relevant object (e.g. a door), the advisor invites the client to help him inspect the object to determine its security state. If the object poses a security threat, then the advisor records it on the list, and captures a photograph of the object using the "Capture Problem" technique (see Figure 1). He explains and discusses the issue with the client using the physical object and/or the photograph using the "ExplainProblem"-technique. He draws on the photograph to highlight the nature of the problem (Figure 2). He selects tags from a tag cloud to record the kinds of security problems the object presents. He types notes about problems not covered by the tag cloud (Figure 2). If the solution is better explained at the physical location of the object, he searches for a solution in his database using the "Find 
Smart Protector

Service Encounter Thinklets
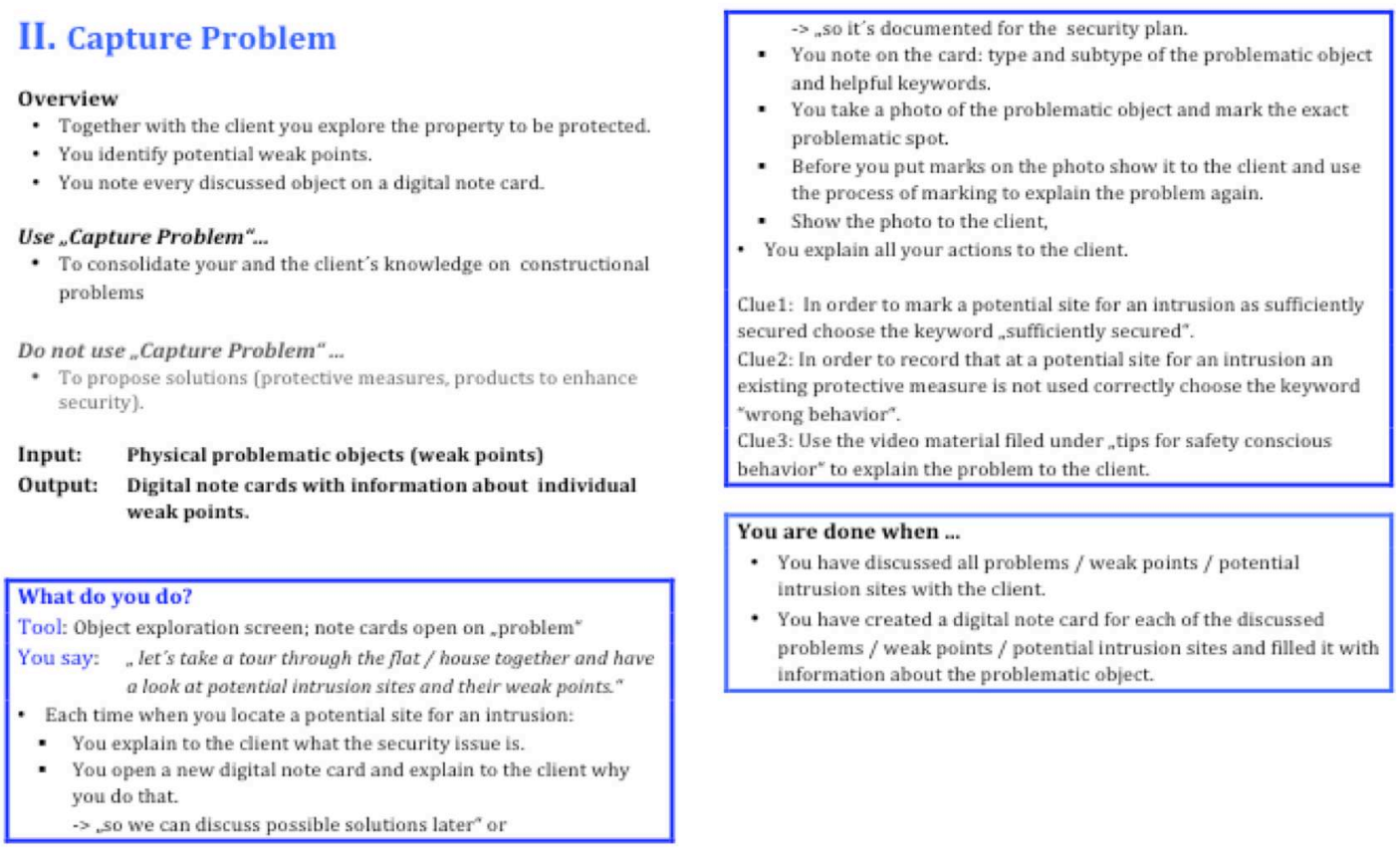

You are done when ...
* You have discussed all problems / weak points / potential
intrusion sites with the client.
* You have created a digital note card for each of the discussed
problems / weak points / potential intrusion sites and filled it with
information about the problematic object.

5

Figure 1: The "Capture Problem" Thinklet

Table 2: Mobile Advisory Service Thinklets

\begin{tabular}{|l|l|l|}
\hline Pattern of Collaboration & ThinkLet Name & \multicolumn{1}{|c|}{ ThinkLet description } \\
\hline $\begin{array}{l}\text { Clarify expectations and } \\
\text { build commitment }\end{array}$ & "Initiate session" & $\begin{array}{l}\text { The advisor introduces himself and presents the overall } \\
\text { advisory process to the client }\end{array}$ \\
\hline Generate security issues & "Determine Needs" & $\begin{array}{l}\text { The client presents her perceived security threats and the } \\
\text { advisor collects them }\end{array}$ \\
\hline $\begin{array}{l}\text { Generate problem descrip- } \\
\text { tions }\end{array}$ & "Capture Problem" & $\begin{array}{l}\text { The advisor and the client explore the property to be } \\
\text { protected. They identify potential weak points. For each } \\
\text { weak point the advisor takes a picture of a security rele- } \\
\text { vant object, marks the problematic area and characteriz- } \\
\text { es the problem. }\end{array}$ \\
\hline $\begin{array}{l}\text { Clarify problem } \\
\text { Reduce } \text { available solutions } \\
\text { to a single choice and gen- } \\
\text { erate solution descriptions }\end{array}$ & "Find Solutions" & $\begin{array}{l}\text { The advisor uses pictures and videos to explain why an } \\
\text { object poses a security threat }\end{array}$ \\
\hline $\begin{array}{l}\text { Clarify solution } \\
\text { The advisor sorts the problems in his preferred manner. } \\
\text { appropriated solution together with the client }\end{array}$ \\
\hline $\begin{array}{l}\text { Evaluate and } \text { organize solu- } \\
\text { tions }\end{array}$ & "Explain Solution" & $\begin{array}{l}\text { The advisor explains how a solution prevents burglary } \\
\text { using pictures or a video }\end{array}$ \\
\hline $\begin{array}{l}\text { Build Commitment to im- } \\
\text { plementation }\end{array}$ & "Close session" & $\begin{array}{l}\text { The advisor and client use a matrix to agree how im- } \\
\text { portant each solution is and when it will be implemented }\end{array}$ \\
\hline
\end{tabular}


Solutions" technique. He explains one or more possible solutions with the client, explaining the pros and cons of each, and recommends a solution to the client using the "Explain Solution" technique. He records his recommendation with the notes about the item.

If the solution would be easier to discuss later, then they do not explore possible solutions during this activity. Throughout the walkthrough, the advisor organizes the security objects according to the kind of solution they will require. This makes the planning phase easier, because a single discussion can address solutions for multiple problems. This activity is also supported by the "Find Solutions" technique. Following a standard procedure at each location serves several purposes: The client can distinguish between important and unimportant security objects by observing whether they are captured in the system or not. Furthermore, the repetition of the procedural steps increases the process transparency allowing the client to actively contribute at the appropriate time [7]. Finally the improved doc-

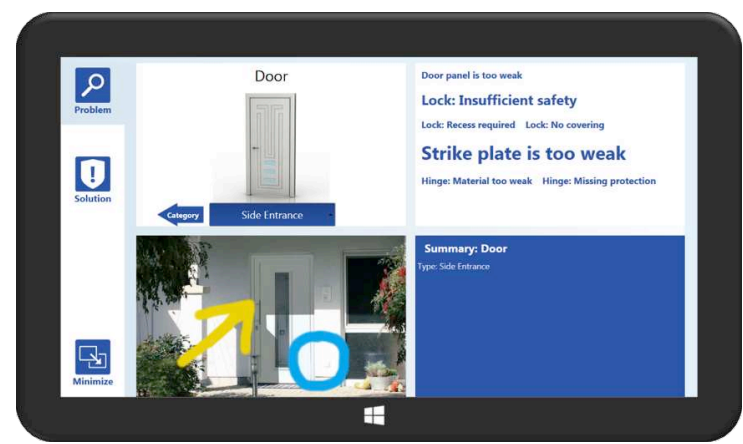

Figure 2: The SmartProtector as it appears during the Exploration Phase

umentation lays the foundation for an improved planning phase. In the first step of this planning phase, the advisor sits down with the client, and walks through each problem item with the client. Where necessary, he searches for and discusses solutions for each problem that was not solved during the exploration phase. The walkthrough retraces the physical exploration path allowing the client to understand the exploration rationale (and thus increasing process transparency). In a second planning step, the advisor and the client develop an implementation plan. For each solution they jointly evaluate the importance of each solution using the "Prioritize Solutions" technique and agree on a deadline by which it should be implemented, given budgetary and other constraints.

After this, the advisor creates a pdf-document of a report containing the complete list of problems elaborated with their recommended solutions and the implementation plan, and emails the report to the client. The advisor then reiterates the value of following through in order to build commitment to execute the plan. The advisor finally asks if there are any other issues that the client can think of. These final problems are typically minor, and are typically dispatched in an oral discussion. If a significant problem emerges, the advisor loops back to the exploration phase. When no more issues remain, the advisor says good-bye.

Collaboration Tools: In the traditional setting, the security advice is just supported by paper brochures and paper for note-taking. For our computer-supported collaborative advisory process, we developed a tabletbased application that we called "SmartProtector".

The designers of advisory tools must support an advisor who simultaneously fulfills two roles: the role of a facilitator, and the role of a subject matter expert [13]. As both of these roles place high demands on the advisor's attention resources, the tools must be simple and intuitive. Because the advisor and client need to vary the order in which they execute activities depending on the local situation and the client's preferences, it is important that support tools do not impose a rigid structure on the order-of-execution for the activities [23]. Our solution therefore suggests a sequence of activities, but allows the advisor to move seamlessly from activity to activity in any order.

Giesbrecht et al. [13] propose the concept of "facilitation affordances" to support the advisory service encounter. A facilitation affordance uses well-known concepts and metaphors that offer and suggest to both the advisor and the client appropriate behaviors for using the tools in an activity. A core affordance of the tool "SmartProtector" is a "notecard". Each notecard represents one security-relevant object that poses one or more security threats (cf. Figure 2).

The SmartProtector runs on a Windows Tablet. The built-in camera allows the advisor to capture the problematic object by taking a picture (in figure 2: a door). The photo is displayed in the app and associated with the object in the underlying database. The application allows the advisor to draw shapes on the picture in order draw attention to security weaknesses. Prefabricated Pictures (upper left) allow users to identify the object (here: a door) and a tag cloud offers typical problems associated with the object (upper right). Selecting problems from a tag-cloud is faster than individually entering problems using the tablet's software keyboard. The font size of the tags reflect the relative frequency of the problem. If a novel issue arises, the advisor can use the keyboard to enter it in the lower right field. Other screens are provided for each of the other aspects of the process. All rely on large pictures and fonts, simple touch-interaction and intuitive metaphors.

Collaborative Behaviors: A collaboration process design comprises intentional restrictions on group pro- 
cesses - restricting people to productive actions that they want to take, and restricting them from counterproductive actions that they do not want to take. Process restrictions can be realized for participants in three ways: technology, guidance, and training [3]. In the SmartProtector, guidance is the primary mechanism for restricting client behavior; training is impossible due to time restriction, and is unnecessary because the advisor chauffeurs the technology, while the client typically only reads from the screen. If the client wants to hold the tablet, the advisor configures the system to be readonly. If the client wants to contribute directly in the application, (edit, change, evaluate), the advisor can grant access and permission.

The technology imposes modest process restrictions on the advisor, in that it offers only capabilities to support actions that the advisor might want and need to take, and no others. For example, the application only offers the capability to take photos in the context of "capturing problems" and not in the context of explaining solutions. Because the advisor works under high cognitive load, however, there are no guidance prompts on the screen suggesting actions that the advisor should or should not take. They learn the other aspects of the process (actions they should take and the constraints), from training. There they learn, for example, that the process works best if they take photos only of security problems, rather than documenting the entire house. They learn in hands-on exercises that extraneous photos significantly increase the cognitive load of all subsequent parts of the advisory session.

The SmartProtector suggests an order of execution for the activities it provides but does not enforce it by restrictions. Advisors rather rely on training. For example, we train the advisors to explain each problem to the client and we offer him suitable tool functionality. But we do not force him to use this tool functionality. He needs this flexibility as a professional to apply the tool in a wide range of situations.

\section{Evaluation Results}

We measured the overall intention to adopt the advisory sessions using the Net-Promoter Score [26] which is a suitable instrument in the service area. On a scale between 1 (worst) and 10 (best), the conventional advice received a score of 7.25. The Net-PromoterScore of the re-engineered process was 8.5. A t-test showed the difference to be statistically significant $(\mathrm{p}=0.038)$.

The ultimate goal of the re-engineering was to improve the implementation ratio of the advice. Thus we evaluated against this goal as advised by Peffers [24]. Rather than testing the intention to implement we fol- lowed the logic of persuasive systems [10] and focused on client "enablement". In analogy to workplace empowerment, we created the concept of "customer empowerment" to measure client enablement. We gathered exploratory data on capability of acting ("I think that I can now work on / solve the discussed issues"), preparing for capability of acting ("I think that the advisory service has prepared me well to address the discussed issues") and suitability ("I regard the advisory result very suited to know, what needs to be done and how I can do it"). We gathered the data on those items using 7 point Likert scales $(1=\mathrm{I}$ do not agree at all, 7 = I completely agree). All three items received statistically significantly higher ratings in the SmartProtector setting (SP) than in the conventional setting (Conv.). Capability of acting was rated 4.83 (conv.) vs. 6.18 (SP, T-Test: $\mathrm{p}=0.04$ ), preparing for capability of acting was rated 5.1 (Conv.) vs. 6.0 (SP, T-Test: $\mathrm{p}=0.02$ ) and suitability was rated 4.92 (Conv.) vs. 6.0 (SP, T-Test: $\mathrm{p}=0.01$ ).

A major reason why the clients felt more empowered lies in the improved comprehensibility of the results ("I have sufficiently understood during the advice session how I need to proceed with solving the issues"). The clients rated the conventional comprehensibility with 5.5 and the SP-comprehensibility with 6.27 (T-Test: $p=0.036$.). The clients also perceived the advisors to have significantly more impact on their behavior (Conv.: 4.5; SP 5.14, T-Test: $\mathrm{p}=0.05$ ). This item is a key item in measuring psychological empowerment in the workplace [32]. Interestingly, there is no significant difference for the same item from the advisors (Conv.: 5.2; SP: 5.8 T-Test: $\mathrm{p}=0.177$ ).

\section{Discussion and Conclusion}

The results indicate that the re-engineered solution was successful: the new advisory process better enables the home owners to make their homes secure. Our results are interesting to several stakeholders. A successful exemplar instance of a generalizable solution to an important class of unsolved problems is a useful contribution to Action Design Research. Researchers may infer that further work would be warranted both to optimize solution designs and to derive the elements that comprise a design theory for collaborative advisory systems, e.g. principles of form and function, the kernel theories, and structured design methodologies. Responsible police agencies may be encouraged to pilot test similar solutions in their cities and states.

There are also implications for Collaboration Engineering as a research domain. This study is an early demonstration that the Six-Layer Model of Collaboration provided a useful conceptual structure for under- 
standing design choices and managing the many interrelated design concerns pertaining to design and deployment of new collaboration systems. It was stimulus, for example for clarifying the group goals of the advisory encounter and cataloging the private goals of the participating stakeholders. (Goals and Deliverables Layers). It structured the analysis of what participants would need to do to succeed (Activities Layer) and guided the logical design of how they would need to do it (Procedures, tools, and Behaviors Layers).

The technological capabilities in the custom-built application were not revolutionary. Other off-the-shelf tools could have provided similar technological features, e.g. a tablet with Microsoft OneNote or WorkdKey. Good tools, however, are only half the story. This was an early instance of packaging technologies so as to transfer a well-engineered, flexible, repeatable collaborative work practice to the practitioners in the field. They became competent practitioners of the process with just one day of training, and afterwards provided significantly improved services. With the SmartProtector, we packaged a collaborative process of eight thinkLets with the required tools to make it obvious how the advisors should behave in each activity. This is a short period considering the often-reported difficulties with changing advisor behaviors in other domains.

For collaboration engineering researchers this paper opens doors to a new domain. Collaboration engineering has been applied to workshop and meeting settings. Now we apply collaboration engineering to the minimal group: two persons. As expert and laymen they have vastly different backgrounds and tasks. Thus the type of thinkLets they need is different. We see more "generate" and "clarify" thinkLets, and fewer "organize" and "reduce" thinkLets. We also note that there is little emphasis in the current canon on collaborative information search - an activity that may be core to mobile and advisory tasks.

Collaboration engineers are presented with a new set of design patterns for dyadic collaboration. This opens new opportunities for them to engineer predictable, repeatable dyadic collaborative processes in this and other domains, for example, energy-advisories $[8,20]$, facility management, or real estate brokerage. While the goals of those activities may differ from security advice, the procedural considerations are similar across domains. All are collaborative, recurring, of high value and with a sufficient number of pain points that it may be worth initiating systematic reengineering projects to address them.

For software engineers, developing tools for mobile users remains a challenge, especially where the primary user (i.e. the advisor) has to simultaneously pay attention to the environment, the device (the tablet) and a collaboration partner. We presented a design that requires so little effort for capturing, organizing and presenting information that the advisors still have sufficient mental resources for the client and the environment. The SmartProtector design fulfills a second purpose. "Facilitation affordances" invite the advisors to appropriate behavior, the way information is presented restricts them from some undesired behaviors, such as leaving out steps or non-transparent collection of information. Due to space restrictions, in this paper we could only present a small fraction of the tool design ideas and of the eight thinkLets. Nonetheless, the paper is sufficient to communicate the overall design rationale of the system. As we worked through the Six Layer Model at design time, we found that the design choices we made at each layer provided the design rationale for the next layer down. The Six Layer Model can provide software developers with compact, deep insights into the sociotechnical design rationale of a new process support application.

At this writing, an extended pilot test of SmartProtector progresses in the City and Canton of Zurich. Four advisors have used it in more than 270 sessions. Authorities just committed to develop a productiongrade version for all Swiss police advisors. The core design of the client-advisor interaction has stabilized, but research continues on integrating it with other processes, e.g. how to establish police-citizen relationships that last beyond an advisory session. Similar efforts in Germany [7] also strive to roll out a workable approach. This requires a new technical architecture to make it more scalable and adjustable to different technical, organizational, informational and legal contexts.

\section{References}

[1] Belkin, N.J., Oddy, R.N., and Brooks, H.M. Ask for information retrieval: Part I. Background and theory. Journal of Documentation 38, 2 (1982).

[2] Briggs, R.O., Kolfschoten, G.L., Vreede, G.J. de, Albrecht, C., Dean, D.L., and Lukosch, S. A six layer model of collaboration for designers of collaboratoin systems. In Collaboration Systems: Concept, Value and Use. Routlege, 2014, 1-14.

[3] Briggs, R.O., Kolfschoten, G.L., de Vreede, G.-J., Lukosch, S., and Albrecht, C.C. Facilitator-in-a-Box: Process Support Applications to Help Practitioners Realize the Potential of Collaboration Technology. Journal of Management Information Systems 29, 4 (2013), 159-194.

[4] Briggs, R.O. and De Vreede, G.-J. ThinkLets: Building Blocks for Concerted Collaboration. Center for Collaboration Science, Omaha, NE, 2009.

[5] Briggs, R.O., De Vreede, G.-J., and Nunamaker Jr, J. Collaboration engineering with ThinkLets to pursue sustained success with group support systems. J. of 
Management Information Systems 19, 4 (2003), 3164.

[6] Brown, D., Pryzwansky, W., and Schulte, A. Psychological consultation and collaboration: Introduction to theory and practice. Allyn \& Bacon, 2005.

[7] Comes, T. and Schwabe, G. From Fuzzy Exploration to Transparent Advice Insights into Mobile Advisory Services. Proceedings of the 49th Hawaii International Conference on System Sciences, (2016).

[8] Dunkelberg, E. and Stiess, I. Energieberatung für Eigenheimbesitzer/innen. Institut für ökologische Wirtschaftsforschung GmbH, 2011.

[9] Fischer, R. and Gerhardt Ralf. The Missing Link between Investors and Portfolios: Introducing Financial Advice. 2007.

[10] Fogg, B.J. A behavior model for persuasive design. Proceedings of the 4th international Conference on Persuasive Technology, ACM (2009).

[11] Gafni, A., Charles, C., and Whelan, T. The physicianpatient encounter: The physician as a perfect agent for the patient versus the informed treatment decisionmaking model. Social Science \& Medicine 47, 3 (1998), 347-354.

[12] Giesbrecht, T., Comes, T., and Schwabe, G. Back in Sight, Back in Mind: Picture-Centric Support for Mobile Counseling Sessions. ACM Press (2015), 486495.

[13] Giesbrecht, T., Schenk, B., and Schwabe, G. Learning with Facilitation Affordances: The Case of Citizens Advice Services. Proceedings of ECIS 2014, (2014).

[14] Heinrich, P., Kilic, M., Aschoff, F.-R., and Schwabe, G. Enabling Relationship Building in Tabletopsupported Advisory Settings. Proceedings of the 17th ACM conference on Computer supported cooperative work \& social computing, (2014).

[15] Heinrich, P., Kilic, M., and Schwabe, G. Microworlds as the locus of consumer education in financial advisory services. ICIS 2014 Proceedings, (2014).

[16] Jungermann, H. Advice giving and taking. Proceedings of the 32nd Annual Hawaii International Conference on System Science, (1999).

[17] Jungermann, H. and Belting, J. Interaktion des als ob: Privatanleger und Anlageberater. Gruppendynamik und Organisationsberatung 35, 3 (2004), 239-257.

[18] Kilic, M. and Dolata, M. How IT-artifacts disturb advice giving - insights from analyzing implicit communication. under review, (2016).

[19] Kolfschoten, G.L., Briggs, R.O., De Vreede, G.-J., Jacobs, P.H., and Appelman, J.H. A conceptual foundation of the thinkLet concept for Collaboration Engineering. International Journal of Human-Computer Studies 64, 7 (2006), 611-621.

[20] Kuchar, F. Entwicklung und Praxistest eines Konzepts für eine EDV- unterstützte 60 Minuten Energieberatung. 2011.

[21] Novak, J., Aggeler, M., and Schwabe, G. Designing large-display workspaces for cooperative travel consultancy. CHI'08 Extended Abstracts on Human Factors in Computing Systems, ACM (2008), 2877-2882.

[22] Nussbaumer, P. Essays on Transparent IT Support for Asymmetric Client-advisor Encounters: The Case of
Swiss Investment Advisory Services. 2012. http://www.merlin.uzh.ch/publication/show/7926.

[23] Nussbaumer, P., Matter, I., and Schwabe, G. "Enforced" vs. "Casual" Transparency-Findings from ITSupported Financial Advisory Encounters. ACM Transactions on Management Information Systems (TMIS) 3, 2 (2012), 11.

[24] Peffers, K., Tuunanen, T., Rothenberger, M.A., and Chatterjee, S. A Design Science Research Methodology for Information Systems Research. Journal of Management Information Systems 24, 3 (2007), 45-77.

[25] Prahalad, C.K. and Ramaswamy, V. Co-creation experiences: The next practice in value creation. Journal of Interactive Marketing 18, 3 (2004), 5-14.

[26] Reichheld, F.F. The one number you need to grow. Harvard business review 81, 12 (2003), 46-55.

[27] Rosson, M.B. and Carroll, J.M. Usability engineering: scenario-based development of human-computer interaction. Morgan Kaufmann, 2002.

[28] Ryan, R.M. and Deci, E.L. Self-determination theory and the facilitation of intrinsic motivation, social development, and well-being. American psychologist 55, 1 (2000), 68.

[29] Schenk, B. and Schwabe, G. Understanding the Advisory Needs of Citizens. (2010).

[30] Sein, M.K., Henfridsson, O., Purao, S., Rossi, M., and Lindgren, R. Action Design Research. MISQ 35, 1 (2011).

[31] Solomon, M.R., Surprenant, C., Czepiel, J.A., and Gutman, E.G. A Role Theory Perspective on Dyadic Interactions: The Service Encounter. The Journal of Marketing 49, 1 (1985), 99-111.

[32] Spreitzer, G.M. Psychological empowerment in the workplace: Dimensions, measurement, and validation. Academy of Management Journal, (1995), 14421465.

[33] Vargo, S.L. and Lusch, R.F. Evolving to a New Dominant Logic for Marketing. The Journal of Marketing 68, 1 (2004), 1-17.

[34] De Vreede, G., Briggs, R.O., and Kolfschoten, G.L. ThinkLets: A Pattern Language for Facilitated and Practitioner-Guided Collaboration Processes. International Journal of Computer Applications in Technology 25, (2006), 140-154.

[35] de Vreede, G.J., Briggs, R.O., and Massey, A.P. Collaboration engineering: foundations and opportunities: editorial to the special issue on the journal of the association of information systems. Journal of the Association for Information Systems 10, 3 (2009), 7.

[36] Warschburger, P. Beratungspsychologie. Medizin Springer Verlag, Heidelberg, 2009. 